\title{
AUTONOMIA E PROTAGONISMO \\ do Sujeito condenado À Pena Privativa de Liberdade
}

\author{
Dissertação de Mestrado \\ Orientadores: Professor Sênior Alvino Augusto de Sá (in memoriam) e \\ Professor Titular Dr. Sérgio Salomão Shecaira
}

Departamento de Direito Penal, Medicina Forense e Criminologia

\author{
Universidade de São Paulo \\ Faculdade de Direito \\ São Paulo - SP


MARIA ISABEL LIMA HAMUD

\title{
AUTONOMIA E PROTAGONISMO
}

\section{do Sujeito condenado À Pena Privativa de Liberdade}

\begin{abstract}
Dissertação de Mestrado apresentada à Banca Examinadora do Programa de PósGraduação em Direito da Faculdade de Direito da Universidade de São Paulo, como exigência parcial para obtenção do título de Mestre em Direito, na área de concentração de Direito Penal, Medicina Forense e Criminologia, sob a orientação do Professor Sênior Alvino Augusto de Sá (in memoriam) e do Professor Titular Doutor Sérgio Salomão Shecaira.
\end{abstract}

Universidade de São Paulo Faculdade de Direito

São Paulo - SP 
MARIA ISABEL LIMA HAMUD

\section{AUTONOMIA E PROTAGONISMO do Sujeito condenado À Pena Privativa de Liberdade}

Dissertação de Mestrado apresentada à Banca Examinadora do Programa de PósGraduação em Direito da Faculdade de Direito da Universidade de São Paulo, como exigência parcial para obtenção do título de Mestre em Direito, na área de concentração de Direito Penal, Medicina Forense e Criminologia, sob a orientação do Professor Sênior Alvino Augusto de Sá (in memoriam) e do Professor Titular Doutor Sérgio Salomão Shecaira.

BANCA EXAMINADORA

Professor Titular Dr. Sérgio Salomão Shecaira

Professor Orientador

Faculdade de Direito da USP

Professor Avaliador

Professor Avaliador

Professor Avaliador

São Paulo, de de 
Em memória de Alvino Augusto de Sá.

Dedicado a meu pai, Osman Mustafá Hamud.

A ausência de ambos se tornou presença e inspiração. 
"A autoridade faz parte de nós, somos o sacerdote, o discípulo, o professor, somos a experiência e o fim."

(JIDDU KRISHNAMURTI)

“O importante não é o que fizeram de nós, mas sim o que nós fazemos daquilo que fizeram de nós."

(JEAN-PAUL SARTRE) 
HAMUD, Maria Isabel Lima. Autonomia e protagonismo do sujeito condenado à pena privativa de liberdade. $180 \mathrm{f}$. Dissertação (Mestrado em Direito) Faculdade de Direito, Universidade de São Paulo, São Paulo, 2020.

\section{RESUMO}

A pesquisa consiste na investigação e análise da noção de autonomia, aplicandoa à Criminologia Clínica, mais especificamente à Criminologia Clínica de Inclusão Social (modelo denominado de "terceira geração", proposto por Alvino Augusto de Sá). Para tanto, debruça-se sobre o conceito filosófico e pedagógico de autonomia, relacionando-o aos estudos acerca do "ator situado", que compreende o indivíduo inserido em seu contexto. A partir daí, coteja a individualização da pena na execução, bem como projetos realizados em unidades prisionais da Secretaria da Administração Penitenciária do Estado de São Paulo, a fim de verificar se consideram a pessoa presa como sujeito autônomo, que assume 0 papel de protagonista durante o cumprimento de sua pena. Por fim, propõe-se estratégias de reintegração social condizentes com o viés da inclusão social.

Palavras-chave: Criminologia Clínica. Inclusão Social. Autonomia. Protagonismo. Reintegração Social. 
HAMUD, Maria Isabel Lima. Autonomy and protagonist of the subject sentenced to deprivation of liberty. $180 \mathrm{f}$. Dissertation (Master) - Faculty of Law, University of São Paulo, São Paulo, 2020.

\section{ABSTRACT}

The research consists of the investigation and analysis of the notion of autonomy, applying it to Clinical Criminology, more specifically to Clinical Criminology of Social Inclusion (model called "third generation", proposed by Alvino Augusto de Sá). Therefore, it focuses on the philosophical and pedagogical concept of autonomy, relating it to studies about the "situated actor", which understands the individual inserted in his context. Thereafter, it compares the individualization of the sentence in the execution, as well as projects carried out in prison units of the São Paulo State Penitentiary Administration, in order to verify whether they consider the prisoner as an autonomous subject, who assumes the role of protagonist while serving his sentence, to then propose Social Reintegration strategies consistent with the Social Inclusion bias.

Key-words: Clinical Criminology, Social Inclusion, Autonomy, Protagonism, Social Reintegration 
HAMUD, Maria Isabel Lima. Autonomie et protagoniste du sujet condamné à la privation de liberté. $180 \mathrm{f}$. Dissertation (Master) - Faculté de Droit, Université de São Paulo, São Paulo, 2020.

\section{RÉSUMÉ}

La recherche consiste en une investigation et analyse de la notion d'autonomie, appliquée au domaine de la Criminologie Clinique, plus spécifiquement la Criminologie Clinique de I'Inclusion Sociale (un modèle appelé «troisième génération», proposé par Alvino Augusto de Sá). Par conséquent, l'accent est placé sur le concept philosophique et psychologique d'autonomie, reliant celui-ci à des études sur «l'acteur situé», qui comprennent l'individu comme étant «inséré dans son propre contexte». Par la suite, la recherche compare l'individualisation dans l'exécution de la sentence, ainsi que des projets réalisés dans les unités pénitentiaires de l'Administration Pénitentiaire de l'État de São Paulo. L'objectif étant de vérifier si le détenu y est considéré comme un sujet autonome, qui assume le rôle de protagoniste tout en purgeant sa peine, pour proposer ensuite des stratégies de Réinsertion Sociale qui s'avèrent cohérentes avec le biais d'Inclusion Sociale.

Mots-clés: Criminologie clinique, Inclusion Sociale, Autonomie, Protagoniste, Réintégration Sociale. 


\section{AGRADECIMENTOS}

Ao mistério da existência, que chamo de Deus.

Aos ausentes: Osman, meu pai, e Alvino, meu orientador, aos quais este trabalho é dedicado. Na esperança e com o profundo desejo de que, de alguma forma, e em algum lugar, se alegrem comigo. Jamais poderia imaginar que tal presença invisível me daria tanta força: a força do amor.

À minha mãe, Maria Emília, que queria que eu tivesse raízes, mas me deu asas; que sofre e se angustia, mas, ainda assim, me permite voar.

À minha irmã, Ana Carolina, que sempre esteve à minha frente, abrindo caminhos, mas também ao meu lado, segurando minha mão quando preciso.

Aos meus padrinhos, Samira e Luis Antônio, assim como à Marina e Luísa, tia Munira, tio Marcelo, Aná Luísa e Alexandre, pelo apoio, por me ensinarem o valor dos estudos e por serem inspiradores, vocês são essenciais.

Ao Thiago Sorelli, por sempre acreditar em mim e por ter trilhado grande parte dessa jornada que se chama vida ao meu lado. Muito do que sou vem de você!

Ao Lacan e à Mellanie, pelo amor quentinho e incondicional de gatos, por me fazerem sorrir. Ao Westlife, pela trilha sonora da vida e por me levarem tão longe.

Às minhas amigas da vida toda, desde sempre e pra sempre, pela presença a despeito de qualquer distância, Thaís, Ellen, Amanda, Andressa, Débora, Mércia, Joana, Mari e Maísa, com vocês a vida tem sentido, beleza e significados.

Ao professor Sérgio Salomão Shecaira, que muito generosamente me acolheu e me orientou em meio à dor da perda do seu amado amigo.

Ao Bruno Shimizu, pela imensa colaboração, leitura atenta, valorosos conselhos, apontamentos, indicações e sugestões; por iluminar o caminho e acreditar em mim.

Ao Bruno Bracco e à Ana Gabriela, pela acolhida e direcionamento na qualificação

Às amigas-irmãs de alma, Natália Sanzovo e Jéssica Pascoal, por sempre acreditarem em mim, desde o auxílio para estudar para a prova de Direito, 
até todo apoio afetivo e emocional. Por toda positividade e otimismo da Naty e por toda sensibilidade e afeto da Jess, vocês são fundamentais na minha vida, pra sempre!

À Mônica, Andressa, Iza, Dani, Lígia, Helena, Luigi, Maurício, Emerson, Lucas (a este também pelo apoio essencial na disciplina do professor Alvino, dias tristes), e toda a trupe GDUCC, por existirem e por serem tão incríveis. Especialmente à Vivian e Tássia por partilharem comigo este momento.

À Natália Peres Corrêa, pela amizade e admiração recíproca, assim como pela ajuda com o resumo em inglês. À Família Pedago Unicamp e Psico Unesp, minhas bases acadêmicas, todo amor. Aos professores que marcaram minha vida, gratidão.

Ao Leonardo Tesser, pela revisão de normas/estrutura e apoio em meio à tensão.

Ao André Luiz Alves, meu diretor, a quem admiro imensamente por sua postura humana e profissional e com quem eu tive e tenho o privilégio de trabalhar, por todo apoio, compreensão, confiança e paciência, por insistir em acreditar em mim.

Ao Ricardo Vieira, o carinho e admiração que nutro por você, por sua integridade, são inenarráveis e imensuráveis; também à Eliane Mariano e à Thaís Gallicia, pela amizade, pelas conversas e por sempre acreditarem em mim e em meus sonhos.

À colega de trabalho que se tornou amiga, Sara Sena, assistente social admirável.

Aos queridos Paulo, Gilson e Juliana, vocês fazem parte importantíssima dessa história.

Aos servidores e detentos do CDP de Mogi das Cruzes, com os quais entre 2009 e 2010 comecei a aprender o que é a prisão.

Aos poucos, raros e preciosos, colegas de trabalho que viveram comigo um período de aprendizado e amadurecimento na Coordenadoria de Reintegração entre 2011 e 2012. Especialmente Eduardo e Silvia, imenso carinho, amizade e admiração!

Aos queridos do CDP IV de Pinheiros, que me acolheram e alegraram meus dias com grandes ensinamentos entre 2013 e 2014. 
Aos que, naquele mesmo CDP, acompanharam meu crescimento profissional e me ajudaram a manter a coerência e nunca perder de vista a realidade no período em que assumi a Diretoria de Saúde, entre 2015 e 2016.

Aos colegas de trabalho que apoiaram meu sonho e compreenderam que "sair da diretoria" não foi um passo para trás, mas sim um passo para o lado, uma mudança de direção, nos anos iniciais do mestrado, 2017 e 2018, ainda em Pinheiros IV.

Aos colegas da Penitenciária I de Guarulhos “José Parada Neto”, pelo apoio e grande aprendizado, especialmente pela oportunidade de assumir o Centro de Reintegração Social e alcançar o lugar que parece ser o mais coerente com a prática profissional à qual me dedico. Às equipes psicossocial e de saúde, tem sido um prazer imenso trabalhar com vocês! Agradeço pelo apoio nesta reta final. À Maria das Dores, a quem tanto admiro e com quem tenho a alegria e o privilégio de compartilhar cotidianamente o trabalho e a amizade. Ao João Batista, Tim Maia, e ao Jean Zocatelli, pela amizade, parceria e apoio, por me ensinarem com tamanha humanidade a visão da segurança.

Ao Villy Fomin, por segurar o espelho na análise dos meus passos nessa trajetória.

Ao Justin Houde, pour le résumé en français, pour l'amour, pour croire en moi, pour croire en nous, pour un possible avenir, pour m'aider à regarder en avant et à rêver. 


\section{SUMÁRIO}

INTRODUÇÃO

1 A CRIMINOLOGIA CLÍNICA DE INCLUSÃO SOCIAL 21

1.10 paradoxo entre os paradigmas da passagem ao ato e da reação social 22

$\begin{array}{ll}1.2 \text { Ator Situado } & 27\end{array}$

1.3 Situação problemática 30

2 AUTONOMIA 37

2.1 O desenvolvimento cognitivo e o senso moral (Jean Piaget e Lawrence Kohlberg) 39

2.2 Da Filosofia à Educação (Immanuel Kant e Paulo Freire) 58

2.3 Autonomia moral e responsabilidade $\quad 64$

3 PROTAGONISMO NA REINTEGRAÇÃO SOCIAL 69

3.1 A relação entre autonomia e protagonismo 72

3.2 Panorama atual da prisão no Estado de São Paulo 81

3.3 Individualização da pena $\quad 84$

3.4 Projetos de Reintegração Social 88

3.4.1 A relação dos projetos com os modelos de Criminologia Clínica 92

3.4.1.1 Eixo I: O Indivíduo 93

3.4.1.2 Eixo II: A família e as relações sociais 101

3.4.1.3 Eixo III: A pena 106

3.4.1.4 Eixo IV: Educação, trabalho e saúde $\quad 119$

3.4.1.5 Eixo V: Funcionários 122

3.4.1.6 Eixo VI: A mulher presa 123

3.5 Propostas condizentes com o modelo de Inclusão Social 125

3.5.1 GDUCC - Grupo de Diálogo Universidade-Cárcere-Comunidade - e a Comunidade Justa $\quad 126$

3.5.2 O trabalho técnico - Psicologia e Serviço Social $\quad 136$

3.5.3. Educação - Leitura e Escrita 142

3.5.4 Trabalho - Sentido e Significado $\quad 147$

3.6 Reintegração social no modelo inclusivo: do ideal ao real 152 CONCLUSÃO 165

BIBLIOGRAFIA 169 


\section{INTRODUÇÃO}

O modelo de Criminologia Clínica de Inclusão Social (ou "de terceira geração"), proposto por Alvino Augusto de Sá, é fruto não só de sua tese de livredocência (2011), mas também - e principalmente - de sua trajetória acadêmica e profissional, tendo atuado como criminólogo clínico, estudioso e docente da área.

Cumpre destacar, para melhor compreensão, a definição de Criminologia Clínica trazida pelo autor, sob o enfoque do paradigma das inter-relações sociais e do modelo de Inclusão Social:

Criminologia Clínica é uma atividade complexa de conhecimentos
interdisciplinares predominantemente científicos, voltada para a
prática profissional. Nessa prática, ela se propõe fazer uma
escuta compreensiva de casos individuais referentes a pessoas
envolvidas com a justiça e, particularmente, a pessoas
encarceradas, bem como fazer uma leitura da dinâmica da
instituição enquanto instância de controle, na qual estão
envolvidas essas pessoas e os profissionais que ali militam. Busca
compreender os comportamentos problemáticos, encarando-os
como expressão de conflitos e confrontos que seus autores têm
em relação às expectativas, normas e valores sociais e culturais, e
também levando em conta seu caráter de lesividade e
conflitualidade na dinâmica que se estabelece entre o autor e a
vítima. Interessa-se por avaliar os desdobramentos possíveis dos
comportamentos problemáticos das referidas pessoas e formular
estratégias que contribuam para que elas tenham um sucesso
saudável, quando de seu retorno ao convívio social livre,
inclusive através da conquista de um melhor equilíbrio
interno e em sua relação com seu contexto social (SA, 2015,
p. 71 , grifo nosso)

A Criminologia Clínica é, portanto, um ramo da Criminologia que tem como foco de estudos e intervenção o sujeito. Para Sá, "a Criminologia Clínica, qualquer que seja seu modelo, jamais poderá abandonar a abordagem do indivíduo, na medida do possível em sua totalidade" (SÁ, 2015, p. 74).

Sabe-se que a Criminologia Clínica carrega o peso de estigmatizar o sujeito devido ao fato de ter consolidado grande parte da produção de conhecimento no modelo médico-psicológico (primeira geração), determinista e causalista, no qual o crime era visto como expressão de uma doença ou desajuste/desequilíbrio e, assim, a intervenção se daria única e exclusivamente sobre o indivíduo. 
De maneira geral, aspectos dessa herança estão ainda hoje impregnados e, em função dessa dívida histórica, criou-se uma certa aversão à Clínica, vez que a busca pelo pretenso criminoso "nato" reforçou uma visão preconceituosa, de cunho estritamente etiológico, tendo gerado segregação e radicalismos. Para Sá:

De fato, clínico, termo que remete originalmente à medicina, tem a
ver com o indivíduo. Daí todo o ranço histórico de poder
comumente atribuído à Criminologia Clínica no sentido dela
buscar uma compreensão do crime centrada nas "causas"
biopsicológicas do indivíduo e desvinculada do contexto
sociológico, ou seja, um saber-poder (de decisão técnica) que
depende somente de seus profissionais e que é dificilmente
contraditado. (SÁ, 2015, p. 74)

Assim, não se deve esquecer que a Criminologia Clínica é apenas um segmento da Criminologia enquanto ciência, de tal feita que o seu desenvolvimento acompanha e é perpassado pelas teorias da Criminologia geral.

Em sua obra Criminologia, Shecaira dedica um capítulo a investigar o nascimento dessa ciência e explana a dificuldade de se apontar uma origem precisa, sendo que o estudo acerca do crime se deu em diversos momentos (inclusive em período por vezes considerado pré-científico, com a Escola Clássica) e por inúmeras ciências (jurídicas, médicas, psicológicas, sociológicas, antropológicas, etc.). Pontua, no entanto, que - deixadas controvérsias de lado seria possível dizer que "a criminologia nasce com o positivismo seja sociológico ou biológico" (SHECAIRA, 2018, p. 77).

As primeiras escolas criminológicas estavam fortemente influenciadas pelo desenvolvimento das ciências biológicas e experimentais, como a Antropologia Criminal de Lombroso e mesmo as contribuições posteriores de seus discípulos, Ferri e Garofalo. Importante salientar, no entanto, que apesar do viés fortemente biologizante, nunca foram desconsiderados o contexto e os fatores ambientais; para Shecaira, a escola positiva "não nega os fatores exógenos, apenas afirma que estes só servem como desencadeadores dos fatores clínicos (endógenos)" (SHECAIRA, 2018, p. 95). Além disso, um erro grave dos estudiosos daquele período foi o de "subvalorizar o entorno social como mero fator desencadeante da criminalidade" (Ibidem, p. 126).

Posteriormente, em oposição ao determinismo biopsicológico da escola positiva italiana, surgiu a perspectiva sociológica. Na segunda metade do século 
XIX, nos Estados Unidos, estava se consolidando uma burguesia industrial, financeira e comercial, acentuando-se assim um desenvolvimento urbano marcado por crescimento populacional desordenado, chegada de imigrantes em busca de trabalho, desigualdade e outros problemas sociais. Em decorrência daquele contexto, já no século XX, a Escola de Chicago despontou como marco inaugural do estudo sociológico do crime e da criminalidade. Daí em diante, inúmeras outras escolas sociológicas elaboraram teorias da criminalidade na visão macrossociológica, sendo que as análises tiveram perspectivas de consenso (visão funcionalista de integração) e de conflito (perspectiva crítica).

Concomitantemente, a Criminologia Clínica passou a incorporar em suas análises a compreensão mais profunda dos aspectos sociais, adotando um modelo posteriormente conhecido como psicossocial (segunda geração). Sá esclarece que:

o critério de diferenciação do modelo psicossocial em relação ao
médico-psicológico não reside simplesmente no grau de
valorização dos fatores ambientais, sociais ou sociológicos.
Reside, primeiramente, no reconhecimento de sua independência,
de sua autonomia, tomando tais fatores como fonte importante na
motivação do crime. Sua importância se deve ao fato de eles
serem independentes e autônomos (isto é, não transformados em
conteúdos psíquicos) na influência que exercem sobre o
direcionamento da conduta criminosa. (SÂ, 2015, p. 184)

Sá, que vivenciou esse período atuando como psicólogo no sistema prisional, traz um importante dado de realidade ao relatar que, durante seu exercício profissional nos cárceres, teve "a oportunidade de observar uma grande resistência que os criminólogos clínicos, de orientação mais estritamente médicopsicológica, têm de aceitar e estudar os fatores extrínsecos aos indivíduos enquanto fatores independentes" (SÁ, 2015, p. 218).

Dentre as teorias sociológicas da Criminologia, foi o movimento conhecido como Labelling Approach (ou Teoria do Etiquetamento Social) que representou uma mudança paradigmática e marcou a emergência das teorias de conflito. Para Shecaira, essa teoria significou "um abandono do paradigma etiológicodeterminista e a substituição de um modelo estático e monolítico de análise social por uma perspectiva dinâmica e contínua de corte democrático" (SHECAIRA, 
2018, p. 242). Tal virada impactou diretamente a Criminologia Clínica. Para Shimizu,

\begin{abstract}
A partir da viragem paradigmática no saber criminológico propiciada pelo enfoque do etiquetamento, a vertente clínica da criminologia, acostumada à intervenção individual sobre o criminoso, passou a ser enxergada como um saber estranho, símbolo da criminologia tradicional, legitimadora da violência penal sobre as classes indesejadas por meio de seus exames biotipológicos, pareceres criminológicos, intervenções psiquiátricas e taxonomias geradoras de desviação. (SHIMIZU, 2016, p. 129)
\end{abstract}

Sá aponta que "nas décadas de 70 e 80, o pensamento humanista e crítico foi identificado com as perspectivas sociológicas e entendeu-se haver uma incompatibilidade entre o 'espírito crítico' e a abordagem psicológica e clínica na criminologia" (SÁ, 2015, p. 265).

Vê-se, assim, que a Criminologia sempre se interessou por investigar os fatores, endógenos e exógenos, condicionantes da conduta criminosa. De um extremo a outro, existem tendências radicalistas. Acontece que ambos os conjuntos de fatores não podem ser isolados. Logo, parece inegável que se relacionam e interagem de forma complexa e dialética entre si.

No primeiro capítulo, expõe-se a base teórica deste trabalho, explanando o paradigma da passagem ao ato (que vê o crime como fato social bruto) e o paradigma da reação social (que vê o crime como uma definição) para melhor compreensão dessas questões.

O modelo de Inclusão Social (terceira geração) da Criminologia Clínica, ancorado no paradigma das inter-relações sociais, aborda ambas as partes (sujeito e sociedade). Também analisa o paradoxo entre o paradigma da passagem ao ato e o paradigma da reação social, que levou à formulação do terceiro (na tentativa de integração dos dois primeiros): o paradigma das interrelações sociais.

Tal modelo vê o crime como fruto de uma expressão de conflito entre o sujeito e a sociedade, entendendo que a reintegração social, enquanto meta a ser atingida, deve ter por fundamento a retomada do diálogo entre as partes conflitantes, sem desconsiderar o paradoxo a ser enfrentado neste processo. Seu 
estudo leva ao desafio de implementar estratégias de reintegração social coerentes com essa proposta.

Sá adota o conceito de "reintegração social" de Alessandro Baratta (1990), sendo essa uma noção que requer a abertura de um processo de comunicação e interação entre o cárcere e a sociedade ${ }^{1}$, de maneira que pessoas presas se reconheçam na sociedade e esta, por sua vez, se reconheça na prisão.

Braga e Bretan (2008) indicam pressupostos que compõe a estratégia de reintegração social proposta por Baratta e que auxiliarão na presente análise. São eles:

A presunção de normalidade do preso, que consiste em tratá-lo como igual a qualquer outra pessoa não-encarcerada;

- A construção de relações simétricas sob uma perspectiva de igualdade, sugerindo que se compartilhe de sua humanidade;

- $\quad$ A participação ativa do sentenciado na escolha e decisão sobre as atividades que irá desempenhar;

- A preocupação com os funcionários da prisão, pois estão inseridos no mesmo contexto e são também atores no cenário da segurança e da reintegração,

- A presença de trabalhos voluntários na dinâmica prisional, o que configura a participação da comunidade.

Tais pressupostos estão de acordo com a visão de uma sociedade inclusiva e com o paradigma das inter-relações sociais, servindo, portanto, como suporte na busca e construção de práticas de reintegração social coerentes com o modelo proposto.

O segundo capítulo da dissertação é dedicado ao principal conceito que figura como tema da pesquisa: a autonomia e sua relação com a noção de responsabilidade. Entende-se que são conceitos fundamentais para a compreensão do sujeito enquanto ator situado, que age e transforma sua realidade dialeticamente ao mesmo tempo em que é transformado por ela.

Isso porque, no percurso de elaboração do modelo de terceira geração, Sá aponta que a moral e a ética são ingredientes indispensáveis da inclusão social. A autonomia é fundamental a partir da compreensão de que ela resulta da

\footnotetext{
${ }^{1}$ Por certo que o cárcere também faz parte da sociedade, servindo tal divisão apenas para diferenciar as parcelas da sociedade que estão ou não encarceradas.
} 
maturidade do senso moral. Além disso, Sá entende que a Criminologia deve ter um compromisso com a visão de valores da humanidade, vez que é "uma ciência que lida com uma realidade profundamente dramática do homem, a realidade do crime, da criminalidade, da violência [...] uma realidade que aglutina os mais profundos conflitos" (SÁ, 2016, p. 173).

Ao abordar os conflitos e buscar uma estratégia eficaz de execução da pena, Sá destaca a importância de que a inclusão social seja a principal meta de qualquer resposta penal. Segundo ele, deve-se entender "inclusão social como forma da expansão do eu, ressignificação e reconstrução de laços, de ressignificação (descoberta própria, via simbolização) de responsabilidades e compromissos morais e éticos, enfim, numa palavra, de projetos consistentes de felicidade" (SÁ, 2015, p. 324).

Considerando a prática profissional da pesquisadora, que atua como psicóloga e criminóloga clínica há cerca de 10 anos no sistema penitenciário paulista, e as inquietações relacionadas ao estigma que a Criminologia Clínica carrega (resultante dos vieses causalista e determinista de sua origem), pretendese resgatar na Criminologia o valor da clínica. Nesta, pretende-se disseminar o entendimento de que o foco da atuação dos profissionais penitenciários, mais especificamente das equipes técnicas (psicólogos e assistentes sociais), deve ser a promoção da autonomia e responsabilidade no sentenciado, propiciando estratégias nas quais o detento possa conhecer a sua individualidade e, consequentemente, assumir (enquanto ator situado) o papel de protagonista de sua reintegração social.

Nesse sentido, o terceiro capítulo contempla o principal objetivo da presente pesquisa: fomentar, a partir do paradigma das inter-relações sociais e dos estudos realizados, caminhos para a individualização da pena durante a execução, além de sugerir programas de reintegração social que propiciem condições ao sujeito para que ele se coloque no papel de protagonista no cumprimento de sua pena e, consequentemente, em sua reintegração social. Para tanto, apresenta projetos realizados nas unidades prisionais do estado de São Paulo, a fim de verificar se adotam pressupostos de autonomia ou de heteronomia e se promovem ou não o protagonismo do sujeito. São analisadas as ações expostas como "boas práticas" pelo site da Coordenadoria de Reintegração Social e Cidadania da Secretaria da Administração Penitenciária do Estado de 
São Paulo, bem como os projetos por ela publicados no Manual de Projetos de Reintegração Social.

Por fim, traz propostas para a manutenção ou implementação do modelo de Inclusão Social no cárcere, resgatando a relação entre autonomia e protagonismo dos sujeitos privados de liberdade. Nesse contexto, o projeto GDUCC (Grupo de Diálogo Universidade-Cárcere-Comunidade) ${ }^{2}$ é contemplado por ser fruto do modelo estudado e por refletir uma iniciativa consonante com aquilo que se mostra construtivo e eficaz na busca por respostas inclusivas de reintegração social, englobando todos segmentos da sociedade.

${ }^{2}$ O projeto, realizado pela Faculdade de Direito da Universidade de São Paulo (USP) enquanto extensão universitária desde 2006, consiste em formar um grupo de cerca de 15 (quinze) a 20 (vinte) alunos que se reúnem semanalmente durante um semestre. Num primeiro momento são realizados cinco encontros teóricos nos quais os alunos debatem textos relacionados à Criminologia Clínica e ao cárcere, bem como sobre diálogo e dinâmicas de grupo. Após esses encontros, o grupo passa a se reunir no cárcere, onde acrescenta cerca de 15 a 20 detentos em sua composição. Os encontros no cárcere servem para consolidar o grupo e permitir a aproximação entre a parcela presa e a parcela não presa da sociedade por meio do diálogo. 


\section{CONCLUSÃO}

A presente pesquisa partiu da indagação a respeito da prática clínica da Criminologia na prisão, ou seja, da atuação dos profissionais técnicos (psicólogos e assistentes sociais) com os sujeitos condenados a penas privativas de liberdade, na busca pela emancipação desses indivíduos, como meta de reintegração social almejada pelo modelo teórico de Criminologia Clínica de Inclusão Social, tendo também pretendido investigar possibilidades concretas de alcançar tal propósito na execução penal.

O foco do trabalho consistiu em investigar a noção de autonomia no âmbito da Criminologia Clínica de Inclusão Social em diálogo com outras ciências (Psicologia, Filosofia e Pedagogia), entendendo que o sujeito autônomo, capaz de governar a si mesmo e nortear sua conduta por princípios universais, torna-se protagonista de sua história.

No percurso trilhado, foi necessário cotejar o paradigma das inter-relações sociais, adotado pela Criminologia Clínica de terceira geração, que abarca o paradoxo e vê o indivíduo enquanto ator situado, inserido num complexo contexto (cenário) no qual se comporta, se relaciona e interage.

Teorias interacionistas do desenvolvimento (Piaget e Kohlberg) auxiliaram na compreensão do processo que leva à almejada autonomia. Foi possível constatar importante relação entre o desenvolvimento cognitivo e o senso moral, pois se verificou que o pensamento autônomo se baseia na capacidade de abstração, vez que envolve reflexões complexas e muitas vezes contraditórias.

Nesse sentido, a pesquisa corroborou a ideia de que o conflito é fundamental ao desenvolvimento e que, portanto, não deve ser resolvido e nem eliminado, mas sim compreendido e acolhido em sua complexidade, o que confirma a visão da Criminologia Clínica de Inclusão Social segundo a qual o crime (o comportamento socialmente problemático, selecionado e tipificado como crime), sendo resultado de uma história dinâmica e complexa de conflitos intra e interpessoais, integra a dinâmica social. Assim, toda a sociedade tem envolvimento e parcela de responsabilidade e, portanto, deve estar envolvida numa efetiva reintegração social da pessoa presa. Justamente por essa razão a inclusão social preza pela aproximação entre sociedade e cárcere. 
No decorrer da pesquisa foi possível perceber que o desenvolvimento da autonomia moral dos sujeitos presos só é possível à medida em que os demais atores envolvidos também tiverem alcançado níveis mais elevados do senso moral, especialmente considerando um contexto social em que a maior parte das relações são heterônomas. Dessa, para fomentar o desenvolvimento da autonomia do outro, é essencial que as pessoas envolvidas nesse processo (profissionais ou não), abandonem projeções, interesses próprios, ameaças de punição e outras condutas típicas de estágios primários do senso moral.

Análises filosóficas e educacionais acerca da ética compuseram o escopo da relação estabelecida entre a autonomia (noção abstrata) e protagonismo (efeito concreto). Por meio da deontologia kantiana e da pedagogia da autonomia freireana foi possível apontar a relação entre a virtude e o fazer, chegando-se ao entendimento de que um sujeito autônomo é, por conseguinte, protagonista: rege suas ações por princípios e se coloca eticamente nas relações e no mundo.

Por fim, no âmbito da execução penal em que se dá a reintegração social, foram analisadas: (1) individualização da pena e (2) desenvolvimento de projetos.

A Criminologia Clínica de Inclusão Social preconiza a individualização da pena por considerar a importância de olhar para o indivíduo enquanto sujeito único em sua identidade, personalidade e historicidade. Ainda assim, paradoxalmente, não deve ser visto e nem tratado de forma isolada, pois atua num contexto complexo e dinâmico de inter-relações.

Foi possível verificar que, se por um lado, a individualização fica prejudicada por questões objetivas, tais como o superencarceramento e a falta de profissionais, por outro, ela é relativamente possível nas atividades grupais, toda vez que a pessoa encontra espaços de expressão e desenvolvimento nas relações. Aqui, viu-se que o papel dos profissionais técnicos deve ser o de facilitar e promover o desenvolvimento pessoal e social do sujeito durante o cumprimento de pena, visando a reinserção social em liberdade.

A análise dos projetos de reintegração social permitiu vislumbrar o quanto as ações desenvolvidas no coletivo são potencialmente transformadoras. Se, por um lado, a maior contradição da prisão é o fato dela segregar para incluir, por outro, foi possível verificar que o exercício da cidadania pode ser realizado mesmo em meio a esse contexto, que não deixa de ser parcela e reflexo da sociedade. 
Sem perder de vista que não é por meio da prisão, mas sim apesar dela, que se busca a reintegração, foram propostas algumas estratégias de intervenção condizentes com as premissas da inclusão social, especialmente no que diz respeito ao desenvolvimento da autonomia, ao exercício do protagonismo e à corresponsabilidade sociedade-cárcere.

Notadamente, a proposta do GDUCC (Grupo de Diálogo Universidade Cárcere - Comunidade), criada e implementada há quase 15 anos pelos professores Alvino Augusto de Sá e Sérgio Salomão Shecaira, é a mais coerente com o modelo apresentado. A presente pesquisa pode contribuir acrescentando a compreensão da técnica da Comunidade Justa proposta por Kohlberg, que sanciona a busca pela meta da inclusão social de atingir o nível pós-convencional de moralidade, descrito por esse mesmo autor.

Foram sugeridas também intervenções profissionais das áreas técnicas, da Psicologia e do Serviço Social, deixando claro que, independentemente da ação desenvolvida, o fundamental é a manutenção de uma postura ética, sustentada frente à responsabilidade pelo conhecimento. Entende-se que os técnicos são criminólogos clínicos e que a eles cabe tanto o exercício profissional quanto o desenvolvimento da Criminologia por meio da praxis. Dessa forma, propõe-se uma mudança radical de conduta, que rompa com o desejo de poder advindo do saber. Uma postura que, ao invés de paternalista ou julgadora, passa a ser de liderança humilde e responsável, havendo interesse genuíno pelo desenvolvimento humano.

A educação e o trabalho, por sua vez, servem à inclusão social na medida em que forem, respectivamente, libertadores e transformadores, repletos de sentido e significados, configurando importantes instrumentos de emancipação do sujeito.

Foi possível perceber que a implementação de práticas inclusivas no cárcere está condicionada à transformação também da sociedade como um todo. Nesse sentido, exige-se um diálogo constante, autêntico, aberto e maduro especialmente com o Direito Penal e com a Política Criminal. Conclui-se com a constatação de que o cárcere poderá ser menos cárcere e, quiçá, não ter necessidade de existir, conforme a sociedade se desenvolva e evolua em sua forma de lidar com os conflitos e contradições a ela inerentes. 


\section{BIBLIOGRAFIA}

AGRA, Cândido. O pensamento clínico de Christian Debuyst: planos de uma trajetória epistêmica. In: DEBUYST, C. Christian. Perspectivas de criminologia clínica. Belo Horizonte: Editora D'Placido, 2018.

BARATTA, Alessandro. Criminologia crítica e crítica do direito penal: introdução à sociologia do direito. Tradução de Juarez Cirino dos Santos. Coleção Pensamento Criminológico. 6. ed. 5. reimpressão. Rio de Janeiro: Revan, 2018.

BARATTA, Alessandro. Ressocialização ou controle social: Uma abordagem crítica da "reintegração social" do sentenciado, 1990. Disponível em: <http://www.egov.ufsc.br/portal/sites/default/files/anexos/13248-13249-1-PB.pdf>. Acesso em: 09 fev. 2020.

BATAGLIA, Patricia Unger Raphael; MORAIS, Alessandra de; LEPRE, Rita Melissa. A teoria de Kohlberg sobre o desenvolvimento do raciocínio moral e os instrumentos de avaliação de juízo e competência moral em uso no Brasil. Estud. psicol., Natal, v. 15, n. 1, p. 25-32, abr. 2010. Disponível em: $<$ http://www.scielo.br/scielo.php?script=sci_arttext\&pid=\$1413-294X20100001000 04\&lng=en\&nrm=iso>. Acesso em: 04 nov. 2019.

BAUMAN, Zygmunt. Identidade: entrevista a Benedetto Vecchi. Tradução de Carlos Alberto Medeiros. Rio de Janeiro: Jorge Zahar Ed., 2005.

BAUMAN, Zygmunt. O Mal Estar na Pós-Modernidade. Tradução de Mauro Gama e Cláudia Martinelli Gama. Rio de Janeiro: Jorge Zahar Ed., 1998.

BAUMAN, Zygmunt. Destino e Caráter. In: 44 cartas do mundo líquido moderno. Tradução de Vera Pereira. Rio de Janeiro: Jorge Zahar Ed., 2011, p. 214-217. 
BECKER, Fernando. Paulo Freire e Jean Piaget: teoria e prática. Schème: Revista eletrônica de Psicologia e Epistemologia Genética. v. 9, edição especial, Marília: UNESP, jul. 2017.

BIAGGIO, Ângela Maria B. Discussões de julgamento moral: Idiossincrasias do caso brasileiro. Rev. Psicologia: Teoria e Pesquisa, Brasília, v. 1, n. 3, p. 195204, 1985.

BIAGGIO, Ângela Maria B. Kohlberg e a "Comunidade Justa": promovendo o senso ético e a cidadania na escola. Psicologia Reflexão e Crítica, Porto Alegre, v. $10, \quad$ n. $1, \quad$ p. 47-69, 1997. Disponível em: <http://www.scielo.br/scielo.php?script=sci_arttext\&pid=S0102-797219970001000 05\&lng=en\&nrm=iso >. Acesso em: 05 nov. 2019.

BRAGA, Ana Gabriela Mendes. Magia no cárcere: a possibilidade do encontro. Boletim IBCCRIM, São Paulo, ano 14, n. 171, p. 11-12, fev. 2007.

BRAGA, Ana Gabriela M.; BRETAN, Maria Emília A. N. Teoria e prática da reintegração social: o relato de um trabalho crítico no âmbito da execução penal. In: SÁ, Alvino Augusto de; SHECAIRA, Sérgio Salomão (Org.). Criminologia Aplicada aos Problemas da Atualidade. São Paulo: Atlas, 2008, p. 255-275.

BRAGA, Ana Gabriela Mendes. Na prisão e contra ela: recusa e resistência. Revista do Conselho Nacional de Política Criminal e Penitenciária, n. 22, Brasília, DF, p. 259-270, 2010.

BRANDÃO, Jack; GUARINIELLO, Silvio Queiroz. Immanuel Kant e Paulo Freire: a escola, os educandos e a questão da autonomia. Lumen et Virtus, v. 8, n. 19, p. 171-193, ago. 2017. Disponível em: <https://www.academia.edu/34234266/ IMMANUEL_KANT_E_PAULO_FREIRE_A_ESCOLA_OS_EDUCANDOS_E_A_Q UEST\%C3\%83O_DA_AUTONOMIA>. Acesso em: 08 nov. 2019.

BRASIL. Governo Federal. Ministério da Justiça e Segurança Pública. Departamento Penitenciário Nacional. Levantamento Nacional de Informações 
Penitenciárias: atualização de junho de 2017. Disponível em: $<$ http://depen.gov.br/DEPEN/depen/sisdepen/infopen/relatorios-sinteticos/infopenjun-2017-rev-12072019-0721.pdf>. Acesso em: 06 jan. 2020.

BRASIL. Governo Federal. Ministério da Saúde. Secretaria de Políticas de Saúde. Área Técnica de Saúde do Adolescente e do Jovem. Protagonismo juvenil: caderno de atividades. Brasília: Ministério da Saúde, 2001.

BRASIL. Lei no 7.210, de 11 de julho de 1984. Institui a Lei de Execução Penal. Disponível em: <http://www.planalto.gov.br/ccivil_03/leis/l7210.htm http://www.planalto.gov.br/ccivil_03/leis/17210.htm>. Acesso em: 08 jan. 2020.

BRESOLIN, Keberson. Autonomia versus heteronomia: o princípio da moral em Kant e Levinas. Conjectura: Filosofia e Educação, Caxias do Sul, v. 18, n. 3, p. 166-183, set./dez. 2013.

BUENO, José Geraldo Silveira; PENNA, Marieta Gouvêa de Oliveira. A docência no ambiente prisional: entre a autonomia e a opressão. Etnográfica, v. 20, n. 2, p. 387-409, 2016. Disponível em: <http://journals.openedition.org/etnografica/4326>. Acesso em: 12 jan. 2020.

CABRAL, Luisa Rocha; SILVA, Juliana Leite. O trabalho penitenciário e a ressocialização do preso no Brasil. Revista CAAP, p. 157-184. Universidade Federal de Minas Gerais: Belo Horizonte, jan./jun. 2010. Disponível em: $<$ https://revistadocaap.direito.ufmg.br/index.php/revista/article/download/277/274>. Acesso em: 25 jan. 2020.

CÂMARA, Heleusa Figueira. Reinvenções da vida em escritas na prisão. Revista Em Aberto, Brasília, v. 24, n. 86, p. 105-126, nov. 2011.

CÂMARA, Heleusa Figueira. Além dos Muros e das Grades: Discursos Prisionais, São Paulo: EDUC, 2001. 
CAMARGO, Liseane Silveira; BECKER, Maria Luíza Rheingantz. O percurso do conceito de cooperação na epistemologia genética. Educ. Real., Porto Alegre, v. 37, n. 2, p. 527-549, mai./ago. 2012.

CIAMPA, Antonio da Costa. Identidade. In: CODO, Wanderley; LANE, Silvia T. Maurer (orgs.). Psicologia social: o homem em movimento. São Paulo: Brasiliense, 1984, p. 58-75.

CIAMPA, Antonio da Costa. A estória do Severino e a história da Severina: um ensaio de psicologia social. São Paulo: Editora Brasiliense, 1987.

COHEN, Cláudio; AUGUSTINIS, Emílio J. É possível a autonomia do sentenciado no sistema penitenciário? Revista Bioética, Brasília, v. 6, n. 1, p. 55-59, 1998.

CORTELLA, Mário Sérgio; LA TAILLE, Yves de. Nos Labirintos da Moral. 11. ed. ampl. Campinas: Papirus, 2017.

COSTA, Antonio Carlos Gomes. Protagonismo juvenil: adolescência, educação e participação democrática. Salvador: Fundação Odebrecht, 2000.

COSTA, Antonio Carlos Gomes. Tempo de servir: o protagonismo juvenil passo a passo - um guia para o educador. Belo Horizonte: Universidade, 2001.

DEBUYST, Christian. Christian Debuyst: perspectivas de criminologia clínica. Belo Horizonte: Editora D'Placido, 2018.

DEBUYST, Christian. Les Paradigmes du dróit penal et les criminologies cliniques. Criminologie, Quebec, v. 25, n. 2. p. 49-72, 1992.

DIGNEFFE, Françoise. Morale de justice ou morale de responsabilité: un débat entre L. Kohlberg et C. Gilligan à propos du développement du jugement moral. Déviance et Société, Louvain-la-Neuve, v. 10. n. 1, p. 21-38, 1986. 
DWORKIN, Ronald. O que é uma vida boa? Rev. Direito GV, São Paulo, v. 7, n. 2. p. 607-616, dez. 2011. Disponível em: $<$ http://www.scielo.br/scielo.php?script=sci_arttext\&pid=S1808-243220110002000 10\&lng=en\&nrm=iso>. Acesso em: 02 nov. 2019.

DUSKA, Ronald; WHELAN, Mariellen. O desenvolvimento moral na Idade Evolutiva: Um Guia a Piaget e Kohlberg. São Paulo: Edições Loyola, 1994.

ELIA, Luciano. O conceito de sujeito. 3 ed. Rio de Janeiro: Zahar, 2010.

FAGUNDES, Antônio Jayro da Fonseca Motta. Cuidados Para a Formulação dos Objetivos de Pesquisa. Revista Educação, v. 3, n. 1, p. 73-81, UNG: 2008.

FERRETTI, Celso J.; ZIBAS, Dagmar M. L.; TARTUCE, Gisela L. B. P. Protagonismo juvenil na literatura especializada e na reforma do ensino médio. Cadernos de Pesquisa, São Paulo, v. 34, n. 122, p. 411-423, mai./ago. 2004. Disponível em: <http://www.scielo.br/pdf/cp/v34n122/22511.pdf>. Acesso em: 01 nov. 2019

FILHO, Armando Lourenço; LIMA, Bárbara C. M. Toledo; GUIMARÃES, Gustavo H. Escobar. Um diálogo entre as concepções de disciplina de Kant, Dewey e Freire. Impulso, Piracicaba, v. 23, n. 56, p. 61-72, jan./abr. 2013. Disponível em: $<$ https://www.metodista.br/revistas/revistas-unimep/index.php/impulso/article/down load/1485/1126>. Acesso em: 08 nov. 2019.

FINI, Lucila Diehl Tolaine. Desenvolvimento moral: de Piaget a Kohlberg. Perspectiva, v. 9, n. 16, p. 58-78, jan./dez. 1991. Disponível em: $\leq h t t p s: / / p e r i o d i c o s$ .ufsc.br/index.php/perspectiva/article/viewFile/9127/10679>. Acesso em: 02 nov. 2019.

FOUCAULT, Michel. Vigiar e Punir: história da violência nas prisões. Tradução de Raquel Ramalhete. 38 ed. Petrópolis: Vozes, 2010. 
FRAGOSO, Tiago de Oliveira. Modernidade líquida e liberdade consumidora: o pensamento crítico de Zygmunt Bauman. Revista Perspectivas Sociais, Pelotas, ano 1, n. 1, p. 109-124, mar. 2011.

FRANKL, Viktor E. Em busca de sentido: um psicólogo no campo de concentração. Tradução de Walter O. Schlupp e Carlos C. Aveline. Revisão de Helga H. Reinhold. 24. ed., Petrópolis: Editora Vozes, 2007.

FREIRE, Paulo. Educação como prática da liberdade. 7. ed. Rio de Janeiro: Paz e Terra, 1977.

FREIRE, Paulo. Pedagogia da autonomia. 58. ed. Rio de Janeiro: Paz e Terra, 2019.

FREITAS, Lia Beatriz de Lucca. Do mundo amoral à possibilidade de ação moral. Psicol. Reflex. Crit., Porto Alegre, v. 12, n. 2, p. 447-458, 1999. Disponível em: $<$ http://www.scielo.br/scielo.php?script=sci_arttext\&pid=S0102-797219990002000 13\&lng=en\&nrm=iso>. Acesso em: 01 nov. 2019.

FREITAS, Lia Beatriz de Lucca. Piaget e a consciência moral: um kantismo evolutivo? Psicol. Reflex. Crit., Porto Alegre, v. 15, n. 2, p. 303-308, 2002. Disponível em: <http://www.scielo.br/scielo.php?script=sci_arttext\&pid=S0102$79722002000200008 \&$ Ing=en\&nrm=iso > Acesso em: 01 nov. 2019.

FREUD, Sigmund. Reflexões para o tempo de guerra e morte (1915). In:

Edição Standard Brasileira das Obras Psicológicas Completas, Vol. XIV. Rio de Janeiro: Imago, 1976, p. 285-310.

FREUD, Sigmund. Alguns tipos de caráter encontrados no trabalho psicanalítico: criminosos em consequência de um sentimento de culpa (1916). In:

Edição Standard Brasileira das Obras Psicológicas Completas, Vol. XIV. Rio de Janeiro: Imago, 1974, p. 375-377. 
FUZIGER, Rodrigo José. Ao arbítrio de Ananke: Por uma revisão do conceito de autodeterminação no Direito penal. 403 p. Tese (Doutorado em Direito) Faculdade de Direito, Universidade de São Paulo, São Paulo, 2018.

GALLIAN, Dante. A literatura como remédio: os clássicos e a saúde da alma. São Paulo: Martin Claret, 2017.

GARZ, Detlef. Lawrence Kohlberg: An Introduction. Barbara Budrich Publishers Opladen \& Farmington Hills, MI, 2009.

GELLIS, André; HAMUD, Maria Isabel Lima. Sentimento de culpa na obra freudiana: universal e inconsciente. Psicol. USP, São Paulo, v. 22, n. 3, p. 635654, set. 2011.

GOFFMAN, Erving. Estigma: notas sobre a manipulação da identidade deteriorada. Tradução de Márcia Bandeira M. L. Nunes. 4. ed. Rio de Janeiro: LTC, 1988.

GUIMARÃES, Thais Albernaz; LUNA, Sergio Vasconcelos de. Projetos de reintegração social do presidiário: uma leitura comportamental. Temas psicol., Ribeirão Preto, v. 21, n. 2, p. 439-449, dez. 2013. Disponível em <http://pepsic.bvsalud.org/scielo.php?script=sci_arttext\&pid=S1413-389X2013000 200011\&lng=pt\&nrm=iso $>$. Acesso em: 02 jan. 2020. http://dx.doi.org/10.9788/TP2013.2-11.

HAMUD, Maria Isabel L. Perícia e avaliação psicológica nas prisões: o exame criminológico. Monografia - Programa de Aprimoramento do Núcleo de Psiquiatria e Psicologia Forense (NUFOR), Instituto e Departamento de Psiquiatria, Hospital das Clínicas, Faculdade de Medicina, Universidade de São Paulo, 2015.

JUBRAM, Renata. Autonomia, resiliência e protagonismo: provocações reflexivas para desenvolver competências. São Paulo: Integrare, 2017. 
KANT, Immanuel. Resposta à Questão: o que é Esclarecimento? (Beantwortung der Frage: Was ist Aufklärung?) Tradução de Márcio Pugliesi. Cognitio, São Paulo, v. 13, n. 1, p. 145-154, jan./jun. 2012. Disponível em: <https://revistas.pucsp.br/index.php/cognitiofilosofia/article/download/11661/8392> Acesso em: 05 nov. 2019.

KANT, Immanuel. Sobre a pedagogia. Tradução de Francisco Cock Fontanella. 2. ed. Piracicaba: Editora Unimep, 1999.

KOHLBERG, Lawrence. Psicologia del Desarrollo Moral. Bilbao: Ed. Desclée de Brouwer, 1992

KOHLBERG, Lawrence. Conscience as principled responsibility: on the philosophy of stage six. In: ZECHA, Gerhard, WEINGARTNER, Paul (Eds). Conscience: An Interdisciplinary view. Salzburg Colloquium on Ethics in the Sciences and Humanities. D. Reidel Publishing Company, p. 03-16, Dordrecht, 1984.

KOURY, Mauro G. Pinheiro. Identidade e pertença: disposições morais e disciplinares em um grupo de jovens. Etnográfica, v. 14, n. 1, p. 27-58, 2010. Disponível em: <https://journals.openedition.org/etnografica/148>. Acesso: 22 nov. 2019.

KOURY, Mauro G. Pinheiro. Enraizamento, pertença e ação cultural. Revista Cronos, v. 2, n. 1, p. 131-137, jan./jun. 2001. Disponível em: <https://periodicos.ufrn.br/cronos/article/view/11322/pdf>. Acesso: 22 nov. 2019

LALANDE, A. Vocabulário técnico e crítico da filosofia. 3. ed. São Paulo: Martins Fontes, 1999.

LOURENÇO, Orlando Martins. Psicología de desenvolvimento moral: teoria, dados e implicações. 3. ed. Coimbra: Almedina, 2002.

MATOS, Erica do Amaral. Cárcere e trabalho: significações, contradições e ambivalências. 2019. 220 p. Dissertação (Mestrado em Direito) - Faculdade de Direito, Universidade de São Paulo, São Paulo, 2019. 
MENDES, Luiz Alberto. Memórias de um sobrevivente. São Paulo: Companhia das Letras, 2001.

MENIN, Maria Suzana S. Desenvolvimento Moral: refletindo com pais e professores In: MACEDO, Lino de (Org.). Cinco Estudos de Educação Moral. Col. Psicologia e Educação. São Paulo: Casa do Psicólogo, 1996, p. 37-104.

MORIN, Edgar et al. A sociedade em busca de valores: para fugir à alternativa entre o cepticismo e o dogmatismo. Lisboa: Instituto Piaget, 1996.

PASQUALINI, Juliana Campregher; MARTINS, Lígia Márcia. Dialética singularparticular-universal: implicações do método materialista dialético para a psicologia. Psicol. Soc., Belo Horizonte, v. 27, n. 2, p. 362-371, ago. 2015. Disponível em: <http://www.scielo.br/scielo.php?script=sci_arttext\&pid=S0102718220150002003

$62 \& \operatorname{lng}=e n \& n r m=i s o>$. Acesso em: 25 jan. 2020. http://dx.doi.org/10.1590/1807$03102015 v 27 n 2 p 362$.

PERES, Urania T. (Org.). Culpa. São Paulo: Editora Escuta, 2001.

PIAGET, Jean. Os Procedimentos da Educação Moral. In: Sobre a Pedagogia: textos inéditos. São Paulo: Casa do Psicólogo, 1998, p. 25-58.

PIAGET, Jean. O juízo moral na criança. Tradução de Elzon Lenardon. 4. ed. São Paulo: Summus, 1994.

PIRES, Álvaro P.; DIGNEFFE, Françoise. Vers un paradigme des inter-relations sociales? Pour une reconstruction du champ criminologique. Criminologie, v. 25, n. 2, p. 13-47, 1992.

PIRES, Álvaro P. A racionalidade penal moderna, o público e os direitos humanos. Novos Estudos - CEBRAP, n. 68, p. 39-60, mar. 2004. 
PIRES, Álvaro P. Des signes de renouveau en criminologie? Criminologie, v. 25, n.2, p. 3-11, 1992.

PIRES, Álvaro P. La criminologie et ses objets paradoxaux: réflexions épistémologiques sur un nouveau paradigme. Déviance et société, v. 17, n. 2, p. 129-161, 1993.

QUEIROZ, Sávio Silveira de; RONCHI, Juliana Peterle; TOKUMARU, Rosana Suemi. Constituição das regras e o desenvolvimento moral na teoria de Piaget: uma reflexão Kantiana. Psicologia Reflexão e Crítica, Porto Alegre, v. 22, n. 1, p.69-75, $2009 . \quad$ Disponível em: <http://www.scielo.br/scielo.php?script=sci_arttext\&pid= S0102-79722009000100010\&lng=en\&nrm=iso>. Acesso em: 03 nov. 2019.

RAZERA, Júlio César Castilho. O desenvolvimento do educando como finalidade da educação: revisitando Kohlberg. Psicol. Soc., Florianópolis, v. 23, n. 1, p. 193196, abr. 2011. Disponível em: <http://www.scielo.br/scielo.php?script=sci_art text\&pid=S0102-71822011000100022\&Ing=en\&nrm=iso >. Acesso em: 02 nov. 2019.

REICHERT, Claudete B; WAGNER, Adriana. Considerações sobre a autonomia na contemporaneidade. Estudos e Pesquisas em Psicologia, Rio de Janeiro, v. 7, n. 3, dez. 2007. Disponível em: <http://pepsic.bvsalud.org/scielo.php?script= sci_arttext\&pid=S1808-42812007000300004\&lng=pt\&nrm=iso>. Acesso em: 28 out. 2019.

RIOS, Sâmara Eller. Trabalho penitenciário: uma análise sob a perspectiva justrabalhista. 148 f. Dissertação (Mestrado em Direito) - Universidade Federal de Minas Gerais, Belo Horizonte, 2009.

SÁ, Alvino Augusto de. Criminologia clínica e execução penal: proposta de um modelo de terceira geração. Col. Saberes Críticos. 2. ed. São Paulo: Saraiva, 2015. 
SÁ, Alvino Augusto de. Criminologia clínica e psicologia criminal. 5. ed. São Paulo: Revista dos Tribunais, 2016.

SÁ, Alvino Augusto de et al. GDUCC - Grupo de Diálogo Universidade Cárcere - Comunidade: uma experiência de integração entre a sociedade e o cárcere. Brasília: Brasil. Ministério da Justiça, 2013.

SALLES, Anamaria Aguiar. Louk Hulsman e o abolicionismo penal. Dissertação (Mestrado em Ciências Sociais) - Pontifícia Universidade Católica de São Paulo, São Paulo, 2011.

SECRETARIA DE ADMINISTRAÇÃO PENITENCIÁRIA DO ESTADO DE SÃO PAULO (SAP). Manual de Projetos de Reintegração Social. Departamento de Reintegração Social Penitenciário. São Paulo: Imprensa Oficial, 2005.

SECRETARIA DE ADMINISTRAÇÃO PENITENCIÁRIA DO ESTADO DE SÃO PAULO (SAP). Manual de Ações em Reintegração Social. Coordenadoria de Reintegração Social e Cidadania. São Paulo: Governo do Estado de São Paulo, 2009. Disponível em: <http://www.reintegracaosocial.sp.gov.br/db/crsckyu/archives/fbd3a352708e47274c600760f28999c6.pdf>. Acesso em: 06 jan. 2020.

SEGRE, M.; SILVA, F. L.; SCHRAMM, F. R. O contexto histórico, semântico e filosófico do princípio de autonomia. Revista Bioética, v. 6, n.1, 1998. Disponível em: <http://www.revistabioetica.cfm.org.br/index.php/revista_bioetica/article/view/ 321/389>. Acesso em: 28 out. 2019.

SHECAIRA, Sérgio Salomão. Criminologia. 7. ed. rev., atual. e ampl. São Paulo: Revista dos Tribunais, 2018.

SHIMIZU, Bruno. Criminologia Psicanalítica: o Mal Estar e a Sociedade Punitiva. Rio de Janeiro: Lumen Juris, 2016. 
SOUZA, Helio José dos Santos. O problema da motivação moral em Kant. São Paulo: Editora UNESP: Cultura Acadêmica, 2009.

TIBURI, Márcia. Como conversar com um fascista: reflexões sobre o cotidiano autoritário brasileiro. 2. ed. Rio de Janeiro: Record, 2015.

WINNICOTT, Donald Woods. A delinquência como sinal de esperança (1967). In: . Tudo começa em casa. São Paulo: Martins Fontes, 2005, p. 81-91.

WINNICOTT, Donald Woods. Tudo começa em casa. Tradução de Paulo Sandler. 2. ed. São Paulo: Martins Fontes, 1996.

WINNICOTT, Donald Woods. Privação e delinquência. 4. ed. São Paulo: Martins Fontes, 2005.

ZAFFARONI, Eugenio Raúl. Em busca das penas perdidas: a perda de legitimidade do sistema penal. 5. ed., 5. reimpressão. Rio de Janeiro: Revan, 2017.

ZATTI, Vicente. Autonomia e educação em Immanuel Kant e Paulo Freire. Porto Alegre: EDIPUCRS, 2007.

ZIMBARDO, Philip. Efeito Lúcifer: como pessoas boas se tornam más. Rio de Janeiro: Record, 2012.

ŽIŽEK, Slavoj. Em defesa das causas perdidas. Tradução de Maria Beatriz de Medina. São Paulo: Boitempo, 2011.

ŽIŽEK, Slavoj. Violência. Tradução de Miguel Serras Pereira. 1. ed. São Paulo: Boitempo, 2014. 